\title{
Rapid psychophysical measurements of orientation discrimination for basic research and for clinical testing
}

\author{
ETHEL MATIN, CAROLINE RUBSAMEN, and PETER SCHREYER \\ Long Island University, Greenvale, New York
}

\begin{abstract}
The yes-no signal-detection task was coupled to an interactive "tracking" procedure to create a rapid method for measuring orientation discrimination in clinical and basic research settings. As is the case in related physiological work, only one stimulus is presented on each trial: No simultaneous or successive matching is involved. Results obtained with this method show that orientation sensitivity for sinusoidal gratings depends on orientation (the "oblique effect") but is independent of spatial frequency.
\end{abstract}

Traditionally, the psychophysical techniques used in measuring orientation discrimination require the presentation of two stimuli on each trial. The stimuli appear simultaneously in some cases and successively in others, but, in both instances, they create retinal conditions that necessarily and fundamentally differ from the conditions used in related physiological work, in which no matching or comparison stimulus is employed.

In view of the widespread use of physiological data and concepts in theoretical treatments of orientation perception, the advantages of trying to maximize the similarity between stimulus conditions in physiological and psychophysical research seem more or less self-evident. Nonetheless, the one-stimulus versus two-stimulus issue has received almost no attention in the orientation discrimination literature. There are presumably many reasons for this interesting "blindspot" in the collective experimental wisdom. At least in part, it seems possible that a critical look at the question has been discouraged by the prospect of time-consuming data collection, with yesno signal detection or constant stimuli being the only psychophysical methods that have been used in the very few reports published to date on one-stimulus procedures (Matin \& Drivas, 1979; Matin, Drivas, \& Valle, 1982; Orban, Vandenbussche, \& Vogels, 1984; Valle, Rivera, \& Matin, 1984). In this note, we outline our explorations with a rapid interactive method for measuring orientation discrimination with a one stimulus per trial task. The method is quite general and would presumably be useful for studying a variety of other discriminations as well.

This research was supported by R01 EY02951 from the National Eye Institute and by an award from the Research Committee of C. W. Post College. The authors' mailing address is: Department of Psychology, C. W. Post Center, Long Island University, Greenvale, NY 11548.

\section{MEASURING TILT DISCRIMINATION WITH PEST}

Essentially, we addressed the issue of combining efficiency with the advantages of a one stimulus per trial task by coupling an orientation discrimination variant of the yes-no signal-detection procedure to Taylor and Creelman's Parameter Estimation by Sequential Testing (PEST) (Green \& Swets, 1974; Taylor \& Creelman, 1967; see Taylor, Forbes, \& Creelman, 1983, for a recent update with references to the literature). As is the case with the better known staircase methods (Cornsweet, 1962), PEST "tracks" the subject's responses rather than presenting prespecified stimulus values in the course of an experimental session.

The subject's task on each trial of the modified PEST we are using is identical to the yes-no signal-detection task used in earlier work from this laboratory. Essentially the "noise alone" stimulus and the "signal + noise" stimulus of the classical detection paradigm are replaced by a stimulus that can assume one of two possible orientations on each trial in a given block of trials. The two orientations are clockwise or counterclockwise with respect to a fixed reference orientation, their angular bisector, which is not presented during the trial. [The procedure is described in detail in Matin \& Drivas, 1979; it is important to note that we are not referring to a forced-choice signal-detection procedure (both stimuli presented on each trial), but a yes-no procedure (one stimulus per trial).] With PEST, which we have implemented with a program controlling a microcomputer-based system, the two stimuli selected for presentation at the beginning of a run are easily discriminable. Subsequently, decisions about when to change the angular difference between the two stimuli (the separation value), which separation to try next, and when to end the run are determined by the subject's responding and by the PEST tracking rules. The latter are 
described in detail in Taylor and Creelman's paper, to which we refer the interested reader. ${ }^{1}$ Although the rules are basically straightforward, they cannot be adequately described in a short note.

Essentially, the program measures the angular difference required between two orientations for $75 \%$ correct identification at a given reference orientation. The latter is previewed at the beginning of the run, where it is presented as a series of 200 -msec flashes, one flash every $4 \mathrm{sec}$. This preview continues until the subject signals readiness for the measurements proper. On each subsequent trial, the stimulus assumes one of two orientations, clockwise or anticlockwise, to the reference orientation viewed prior to the measurements. After an $800-\mathrm{msec}$ response period, during which the subject signals whether the stimulus was perceived as clockwise or anticlockwise, auditory feedback about the true physical orientation is delivered. This feedback assists the subject in learning the discrimination and helps to counteract possible tendencies toward a response bias. Indeed, with the procedures we have used-feedback on each trial and .5 probability for each of the two stimuli-subjects have behaved in an essentially unbiased way, thus obviating the necessity for ROC curves.

Our variant of PEST has required an average run of 70 trials. For the trial duration used $(4 \mathrm{sec})$, the corresponding measurement time (including the preview of the reference orientation) is approximately $5 \mathrm{~min}$. Even shorter times can be achieved, however, by reducing trial duration. No loss in sensitivity is expected, because performance in the yes-no task does not depend on duration, at least over the range from 2-8 sec (Valle, Rivera, \& Matin, 1984). The reader also should be aware that PEST's tracking parameters can be chosen to emphasize speed or accuracy, depending on application.

\section{SOME RESULTS}

For simplicity, the tracking procedure's outcome (angular separation for $75 \%$ correct identification) will be treated as the just noticeable difference (JND) in the ensuing description of results obtained with PEST. No further statistical processing is necessary in clinical studies or in research concerned primarily with substantive sensory issues. ${ }^{2}$ The stimulus for all measurements described in this paper was a round, 3.68 cycles per degree (cpd) sinusoidal grating, with a contrast of $60 \%$. It was presented monocularly as a $200-\mathrm{msec}$ flash, which replaced a homogeneous adaptation field identical to the grating in shape, in size $\left(2.65^{\circ} \mathrm{diam}\right)$, and in luminance $\left.26 \mathrm{~cd} / \mathrm{m}^{2}\right)$.

In our first study with PEST, we examined the oblique effect, using eight observers. Three were practiced (P) and five were naive $(\mathrm{N})$ when the study began. For both groups, we ran one familiarization session and then proceeded to obtain two monocular JNDs for the left and right eyes at five reference orientations $\left(0^{\circ}, 30^{\circ}, 45^{\circ}\right.$, $\left.60^{\circ}, 90^{\circ}\right)$. Inspection of the data showed no large or sys- tematic differences between the two eyes, so the four JNDs at each reference orientation were averaged for the results shown in Table 1.

The results of a study of orientation sensitivity as a function of spatial frequency with the tracking method are shown in Table 2 . In that experiment, the data showed that orientation sensitivity is independent of spatial frequency (at least for gratings between 1.8 and $17.7 \mathrm{cpd}$ ). Similar trends were described by Caelli, Brettel, Rentschler, \& Hilz (1983), in the only other report on orientation sensitivity as a function of spatial frequency that has appeared to date. However, their method-of-adjustment procedure with a two stimulus-per-trial task yielded JNDs that are very much larger than ours. Caelli et al. suggest that their large JNDs, relative to those previously reported in the literature, might have resulted from the use of grat-

Table 1

Mean JNDs at the Main Meridians and at Three Obliques

\begin{tabular}{|c|c|c|c|}
\hline Subject & $\begin{array}{c}\text { Reference } \\
\text { Orientation }\end{array}$ & Mean JND & SE \\
\hline $\mathrm{JB}(\mathrm{N})$ & $\begin{array}{r}0 \\
30 \\
45 \\
60 \\
90\end{array}$ & $\begin{array}{l}0.83 \\
2.53 \\
1.40 \\
2.55 \\
0.80\end{array}$ & $\begin{array}{l}0.18 \\
0.88 \\
0.47 \\
0.43 \\
0.17\end{array}$ \\
\hline $\mathrm{HD}(\mathrm{N})$ & $\begin{array}{r}0 \\
30 \\
45 \\
60 \\
90\end{array}$ & $\begin{array}{l}1.18 \\
6.53 \\
4.23 \\
6.23 \\
1.38\end{array}$ & $\begin{array}{l}0.26 \\
1.58 \\
0.88 \\
1.76 \\
0.23\end{array}$ \\
\hline $\mathrm{BK}(\mathrm{N})$ & $\begin{array}{r}0 \\
30 \\
45 \\
60 \\
90\end{array}$ & $\begin{array}{l}1.20 \\
4.00 \\
2.60 \\
4.43 \\
1.85\end{array}$ & $\begin{array}{l}0.24 \\
1.08 \\
0.53 \\
0.72 \\
0.39\end{array}$ \\
\hline $\mathrm{RP}(\mathrm{N})$ & $\begin{array}{r}0 \\
30 \\
45 \\
60 \\
90\end{array}$ & $\begin{array}{l}0.85 \\
3.58 \\
3.38 \\
3.05 \\
0.95\end{array}$ & $\begin{array}{l}0.13 \\
0.94 \\
0.38 \\
0.74 \\
0.10\end{array}$ \\
\hline $\mathrm{GS}(\mathrm{N})$ & $\begin{array}{r}0 \\
30 \\
45 \\
60 \\
90\end{array}$ & $\begin{array}{l}0.73 \\
5.63 \\
5.65 \\
4.55 \\
1.05\end{array}$ & $\begin{array}{l}0.10 \\
0.72 \\
0.81 \\
0.45 \\
0.17\end{array}$ \\
\hline NL(P) & $\begin{array}{r}0 \\
30 \\
45 \\
60 \\
90\end{array}$ & $\begin{array}{l}1.18 \\
3.03 \\
2.85 \\
2.78 \\
0.97\end{array}$ & $\begin{array}{l}0.31 \\
0.57 \\
0.83 \\
0.92 \\
0.38\end{array}$ \\
\hline $\mathrm{EM}(\mathrm{P})$ & $\begin{array}{r}0 \\
30 \\
45 \\
60 \\
90\end{array}$ & $\begin{array}{l}1.17 \\
4.20 \\
3.18 \\
2.23 \\
1.03\end{array}$ & $\begin{array}{l}0.12 \\
0.68 \\
1.10 \\
0.56 \\
0.14\end{array}$ \\
\hline $\mathrm{CR}(\mathrm{P})$ & $\begin{array}{l}.0 \\
30 \\
45 \\
60 \\
90\end{array}$ & $\begin{array}{l}0.85 \\
1.23 \\
1.70 \\
2.10 \\
0.33\end{array}$ & $\begin{array}{l}0.10 \\
0.40 \\
0.41 \\
0.22 \\
0.10\end{array}$ \\
\hline
\end{tabular}

Note-The eight subjects are identified as practiced $(P)$ or naive $(N)$. 
Table 2

PEST Tracked Mean JNDs as a Function of Orientation and Spatial Frequency

\begin{tabular}{|c|c|c|c|c|c|}
\hline & \multirow[b]{3}{*}{ cpd } & \multicolumn{4}{|c|}{ Reference Orientation } \\
\hline & & \multicolumn{2}{|c|}{90} & \multicolumn{2}{|l|}{45} \\
\hline & & Mean JND & SE & Mean JND & SE \\
\hline $\mathrm{DS}(\mathrm{N})$ & $\begin{array}{r}1.80 \\
3.68 \\
6.44 \\
8.47 \\
12.47 \\
17.64\end{array}$ & $\begin{array}{r}1.05 \\
.75 \\
1.12 \\
.60 \\
.95 \\
.65\end{array}$ & $\begin{array}{l}.6608 \\
.2061 \\
.1030 \\
.2165 \\
.1500 \\
.2362\end{array}$ & $\begin{array}{l}2.12 \\
1.85 \\
1.85 \\
2.68 \\
2.63 \\
4.90\end{array}$ & $\begin{array}{l}.2780 \\
.3403 \\
.4349 \\
.5720 \\
.6506 \\
.4320\end{array}$ \\
\hline $\mathrm{EM}(\mathrm{P})$ & $\begin{array}{r}1.80 \\
3.68 \\
6.44 \\
8.47 \\
12.47 \\
17.64\end{array}$ & $\begin{array}{r}.70 \\
.98 \\
1.00 \\
.75 \\
.90 \\
1.30\end{array}$ & $\begin{array}{l}.1632 \\
.2286 \\
.0408 \\
.1892 \\
.2121 \\
.2738\end{array}$ & $\begin{array}{l}1.40 \\
1.62 \\
1.45 \\
1.48 \\
1.35 \\
2.25\end{array}$ & $\begin{array}{l}.1581 \\
.0750 \\
.5567 \\
.2165 \\
.0645 \\
.4213\end{array}$ \\
\hline $\mathrm{CR}(\mathrm{P})$ & $\begin{array}{r}1.80 \\
3.68 \\
6.44 \\
8.47 \\
12.47 \\
17.64\end{array}$ & $\begin{array}{l}.68 \\
.72 \\
.40 \\
.45 \\
.65 \\
.80\end{array}$ & $\begin{array}{l}.1493 \\
.1314 \\
.0500 \\
.0279 \\
.1554 \\
.1290\end{array}$ & $\begin{array}{l}1.10 \\
1.40 \\
1.22 \\
1.90 \\
1.98 \\
2.00\end{array}$ & $\begin{array}{l}.2160 \\
.5017 \\
.3092 \\
.2121 \\
.1547 \\
.5115\end{array}$ \\
\hline $\mathrm{MH}(\mathrm{P})$ & $\begin{array}{r}1.80 \\
3.68 \\
6.44 \\
8.47 \\
12.47 \\
17.64\end{array}$ & $\begin{array}{l}1.28 \\
1.10 \\
1.25 \\
1.30 \\
1.38 \\
1.25\end{array}$ & $\begin{array}{l}.2061 \\
.1632 \\
.1376 \\
.2160 \\
.3250 \\
.2661\end{array}$ & $\begin{array}{l}2.22 \\
1.78 \\
2.18 \\
2.00 \\
2.30 \\
1.93\end{array}$ & $\begin{array}{l}.3637 \\
.2954 \\
.1376 \\
.2380 \\
.1080 \\
.5662\end{array}$ \\
\hline
\end{tabular}

ings instead of lines or slits; however, the gratings cannot account for their results, because we obtained much smaller JNDs with similar stimuli. It seems more likely that their psychophysical technique was responsible for the atypically large values. In any event, both their study and ours yielded the same surprising independence of orientation sensitivity and spatial frequency. The theoretical significance of that finding, along with further data on the question, will be considered in another report.

As can be seen from Tables 1 and 2, the PEST measurements showed a very sizable oblique effect in all subjects, as we have also found in other studies with much more time-consuming methods. This robustness of the oblique effect of orientation sensitivity with a high-contrast stimulus is typical of experimental findings from the time that orientation anisotropy was first discovered (see Matin \& Drivas, 1979, and Valle et al., 1984, for references). The oblique effect of contrast sensitivity, on the other hand, appears to be a much more labile phenomenon (e.g., Mayer, 1983; Williams, Booth, Kiorpes, \& Teller, 1981). Although the reasons for this interesting difference need to be explored, it seems likely that the sturdy orientationdiscrimination effect will prove preferable to other less substantial manifestations of the orientation anisotropy for studies designed to clarify the significance of the oblique effect in the two-dimensional Fourier approach to spatial vision, and for studies concerned with correlations between neural responses and psychophysical performance. The robustness of this phenomenon in normal observers also suggests that it might be a promising candidate for use in clinical tests of vision (see Enoch \& Williams, 1983).

\section{REFERENCES}

Caelli, T., Brettel, H., Rentschler, I., \& Hilz, R. (1983). Discrimination thresholds in the two-dimensional spatial frequency domain. Vision Research, 23, 129-134.

Cornsweet, T. (1962). The staircase method in psychophysics. American Journal of Psychology, 75, 485-491.

ENoch, J., \& Williams, R. (1983). Development of clinical tests of vision: Initial data on two hyperacuity paradigms. Perception \& Psychophysics, 33, 314-322.

GreEN, D., \& SwETS, J. (1974). Signal detection theory and psychophysics (2nd ed.). Huntington: Krieger.

MatiN, E., \& Drivas, A. (1979). Acuity for orientation measured with a sequential recognition task and signal detection methods. Perception \& Psychophysics, 25, 161-168.

Matin, E., Drivas, A., \& Valle, V. (1982). Conditioned tilt naming: A modified absolute judgment method is used to measure the oblique effect. Perception \& Psychophysics, 31, 421-428.

MAYeR, M. (1983). Practice improves adults' sensitivity to diagonals. Vision Research, 23, 547-550.

Orban, G., VANDENBussche, E., \& Vogels, R. (1984). Human orientation discrimination tested with long stimuli. Vision Research, 24, 121-128.

Taylor, M., Forbes, S., \& Creelman, C. (1983). PEST reduces bias in forced choice psychophysics. Journal of the Acoustical Society of America, 74, 1367-1374.

Taylor, M., \& Creelman, D. (1967). PEST: Efficient estimates on probability functions. Journal of the Acoustical Society of America, 41, 782-787.

Valle, V., Rivera, M., \& Matin, E. (1984). Effects of intertrial interval, orientation, and adaptation on orientation discrimination measured with a yes-no signal detection paradigm. Perceptual \& Motor Skills, 59, 743-748.

Williams, R., Boothe, R., KiorPes, L., \& Teller, D. (1981). Oblique effects in normally reared monkeys (macaca nemestrina): Meridional variations in contrast sensitivity measured with operant techniques. Vision Research, 21, 1253-1266.

\section{NOTES}

1. Taylor and Creelman (1967) illustrate PEST with auditory threshold measurements requiring a two-alternative forced choice on each trial. However, the forced-choice task is not a necessary part of the tracking procedure. At the risk of belaboring a point that we hope is by now obvious, our PEST variant employs the one-stimulus yes-no task, not the two-stimulus forced choice.

2 . Assuming homogeneity of variance, normality of the two underlying distributions, and an equal bias criterion, $75 \%$ correct implies a discriminability index $\left(\mathrm{d}^{\prime}\right)$ of 1.35 . When the reciprocal of the psychometric function's slope is used as the JND (as in Matin \& Drivas, 1979; Orban et al., 1984; and Valle et al., 1984), the corresponding $d^{\prime}$ is 1 . Our decision to use the $75 \%$ point without further statistical processing was heavily influenced by recently published suggestions about the development of procedures that are suitable for clinical work (Enoch \& Williams, 1983). 